\title{
Modeling phase diagrams of systems containing ionic liquids used in different applications
}

\author{
Y.S. Chen, F. Mutelet, and J-N. Jaubert \\ Laboratoire Réactions et Génie des Procédés (LRGP), Université de Lorraine, Nancy 54000, France
}

\section{Introduction}

Ionic liquids (ILs) [1], organic salts with melting points around or below ambient temperature, have been used as green solvents, owing to their interesting physicochemical properties: negligible vapour pressure, high chemical and thermal stabilities, and recyclability. Moreover, they are able to dissolve a wide range of organic or inorganic substances, and it is possible to adjust some of their properties such as polarity or miscibility by employing different cation-anion combinations [2-6]. For all these reasons, ILs are being postulated as promising alternative solvents for a number of technological applications in the context of green processes such as the absorption of carbon dioxide and the extractive desulfurization of diesel oil.

Thermodynamic properties of ILs can be obtained by experimental techniques and/or simulations. The main advantage of the use of an equation of state versus the other techniques is the speed and efficiency in which these calculations are performed. An equation of state such as PC-SAFT (Perturbed Chain-Statistical Associating Fluid Theory) [7] based on statistical mechanics offers several advantages. The first advantage is that each of the approximations made in the development of SAFT such as the chain and association terms has been verified from molecular simulation results. In this way, the range of applicability and the shortcomings of each term in the equation of state have been assessed. Moreover, the SAFT parameters have a physical meaning. The PC-SAFT is a useful tool in which the effects of molecular structure on the thermodynamic properties can be separated and quantified. For example, non-ideal contributions such as chain length and/or molecular shape, molecular association and polar interactions can be introduced in the development of the equation.

In this work, we present the application of the PCSAFT equation of state to model phase diagrams of systems containing ILs. The first part of this work consists on an experimental section including vaporliquid equilibrium (VLE) measurement for binary systems containing $\left\{\right.$ ILs $\left.+\mathrm{CO}_{2}\right\}$ and $\{$ ILs+ pyridine $\}$. In a second part, the experimental data were correlated with the PC-SAFT model and accurate prediction was obtained for the two binary systems.

\section{Experimental}

\subsection{Materials}

Carbon dioxide was purchased from Messer with a purity of 0.99 in mass fraction. The ILs studied in this work: 1 , 3-dimethylimidazolium methylphosponate [DMIM] $[\mathrm{Ph}]$ (purity $>98 \%$ ) was obtained from Solvionic, 1-ethyl-3methylimidazolium thiocynate [EMIM][SCN] (purity $>95 \%$ ) was supplied by Fluka, trihexy(tetradecy)phosphonium dodecylbenzenesulfonate [THTDP] $\left[\mathrm{C}_{12} \mathrm{H}_{25} \mathrm{PhSO}_{3}\right]$ (purity>98\%) and 1-butyl-3-methylimidazolium diethyleneglycolmonomethylethersulfate $[\mathrm{BMIM}] \quad\left[\mathrm{MDEGSO}_{4}\right]$ (purity $>98 \%$ ) were supplied by STREM Chemicals Inc..

\subsection{Apparatus and Procedure}

\section{VLE measurements for $\{\mathrm{CO} 2+$ ILs $\}$}

Bubble point pressures of the systems $\left\{\mathrm{CO}_{2}+\mathrm{IL}\right\}$ were measured using a high-pressure variable-volume visual cell (Top Industry, S.A.) shown in Figure 1. The technique used to carry out phase equilibrium measurements was based on a synthetic method which avoids sampling and analyses of the phases. 


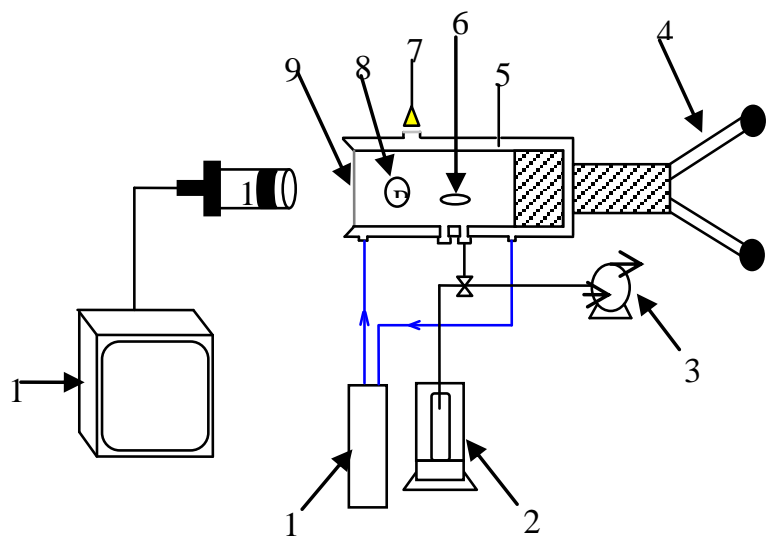

Figure 1. Schema of the VLE apparatus. 1: Thermostated Bath; 2: Analytical Balance; 3: Vacuum Pump; 4: Piston; 5: Temperature Probe (Pt100); 6: Magnetic stirrer; 7: Light source; 8: Calibrated pressure sensor $(0<\mathrm{P}<340 \mathrm{bar})$; 9 : Sapphire window; 10: Video camera; 11: Monitor.

\section{VLE measurements for \{pyridine + ILs\}}

VLE measurements of \{pyridine + ILs \} have been performed in a glass cell by using a static method. The apparatus is shown schematically in Figure 2. This apparatus can be applied for the measurement of reliable isothermal P-x data up to $298 \mathrm{~K}$ and $40 \mathrm{kPa}$.

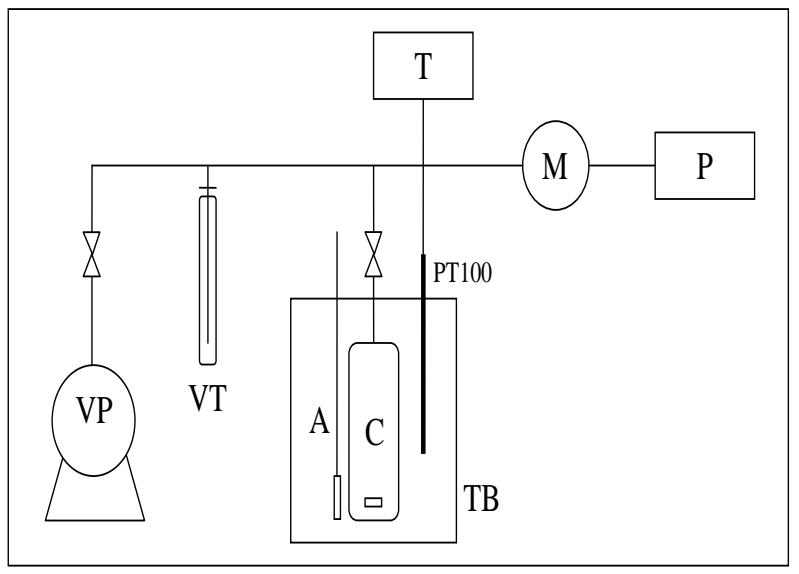

Figure 2. Schema of the VLE apparatus: VP: Vacuum Pump; VT: Vacuum Trap; A: Magnetic stirrer; C: Equilibrium Cell; PT-100: Platinum resistance Thermometer; T: Temperature Indicator, M: Calibrated Pressure Sensor, P: Digital Pressure Indicator and TB: Thermostated Bath.

\section{Modeling}

The Perturbed Chain-Statistical Associating Fluid Theory (PC-SAFT) EoS has been developed in 2001 by Gross and Sadowski [7]. The PC-SAFT equation is usually written in terms of the residual Helmholtz energy. Each term in the equation represents different microscopic contributions to the total free energy of the fluid. The equation writes:

$\tilde{a}^{r e s}=\tilde{a}^{h c}+\tilde{a}^{d i s p}+\tilde{a}^{a s s o c}$ where $\tilde{a}^{\text {res }}$ is the residual Helmholtz free energy of the system. The superscripts $h c$, disp and assoc refer to a reference hard chain contribution, a dispersion contribution and an associating contribution, respectively. Equations are as follows:

$$
\begin{aligned}
& \tilde{a}^{h c}=\bar{m} \tilde{a}^{h s}-\sum_{i=1}^{n_{c}} x_{i} m_{i}-1 \ln g_{i j}^{h s} \\
& \tilde{a}^{\text {disp }}=-2 \pi \tilde{\rho} I_{1} \overline{m^{2} \varepsilon \sigma^{3}}-\pi \tilde{\rho} \bar{m} C_{1} I_{2} \overline{m^{2} \varepsilon^{2} \sigma^{3}} \\
& \tilde{a}^{\text {assoc }}=\sum_{i=1}^{n c} x_{i}\left[\sum_{A_{i}}\left(\ln X^{A_{i}}-\frac{X^{A_{i}}}{2}\right)+\frac{1}{2} M_{i}\right]
\end{aligned}
$$

For evaluating the phase behaviour of the $\left\{\mathrm{CO}_{2}+\mathrm{ILs}\right\}$ and \{pyridine + ILs\} systems, five parameters: the segment number $(m)$, the segment energy $\left(\varepsilon / k_{B}\right)$, the segment diameter $(\sigma)$, the association energy $\left(\varepsilon^{A_{i} B_{j}}\right)$ and the association volume $\left(k^{A_{i} B_{j}}\right)$ are required to characterize each compound. More details about PCSAFT equation of state have been described in our previous publication [8].

\section{Results}

The PC-SAFT parameters of pure ILs were determined using experimental densities measured in our laboratory. Carbon dioxide was modelled as a non-associating substance and represented by three molecular parameters: $m, \sigma$ and $\varepsilon / k_{B}$. The values of these three parameters are taken from the literature [9]. The PCSAFT parameters of pure ILs were determined considering them as self-associating compounds. The three non-associating parameters $\left(m, \sigma, \varepsilon / k_{B}\right)$ and two self-associating parameters $\left(\varepsilon^{A_{i} B_{j}}\right.$ and $\left.k^{A_{i} B_{j}}\right) \quad$ were obtained by a fitting procedure on pure-component data. Parameters of pyridine were obtained from literature [10]. Results for molecular parameters of carbon dioxide, ILs and pyridine with absolute average deviation (AAD \%) on density are provided in Table 1.

We now present and discuss calculations performed with the PC-SAFT EoS to correlate VLE data on systems containing $\left\{\mathrm{CO}_{2}\right.$ or Pyridine $\left.+\mathrm{IL}\right\}$. Interaction parameter $\mathrm{k}_{\mathrm{ij}}$ was fitted on experimental VLE data. Firstly, we studied the mixture $\left\{[\mathrm{BMIM}]\left[\mathrm{MDEGSO}_{4}\right]+\mathrm{CO}_{2}\right\}$ at different temperatures: $\mathrm{T}=313.15 \mathrm{~K}, \mathrm{~T}=323.15 \mathrm{~K}$, $\mathrm{T}=333.15 \mathrm{~K}, \mathrm{~T}=343.15 \mathrm{~K}, \mathrm{~T}=353.15 \mathrm{~K}$ and $\mathrm{T}=363.15 \mathrm{~K}$. Figure 3 depicts the experimental data but also the calculated phase diagrams using the PC-SAFT equation of state. It's striking to see the accuracy of these calculations as compared to the experimental data. Results obtained on the binary mixture $\left\{\mathrm{CO}_{2}+\right.$ $\left[\right.$ THTDP] $\left.\left[\mathrm{C}_{12} \mathrm{H}_{25} \mathrm{PhSO}_{3}\right]\right\}$ are presented in Figure 4. A good agreement between experimental VLE data and the calculated values is observed. 
Table 1. PC-SAFT parameters of different compounds.
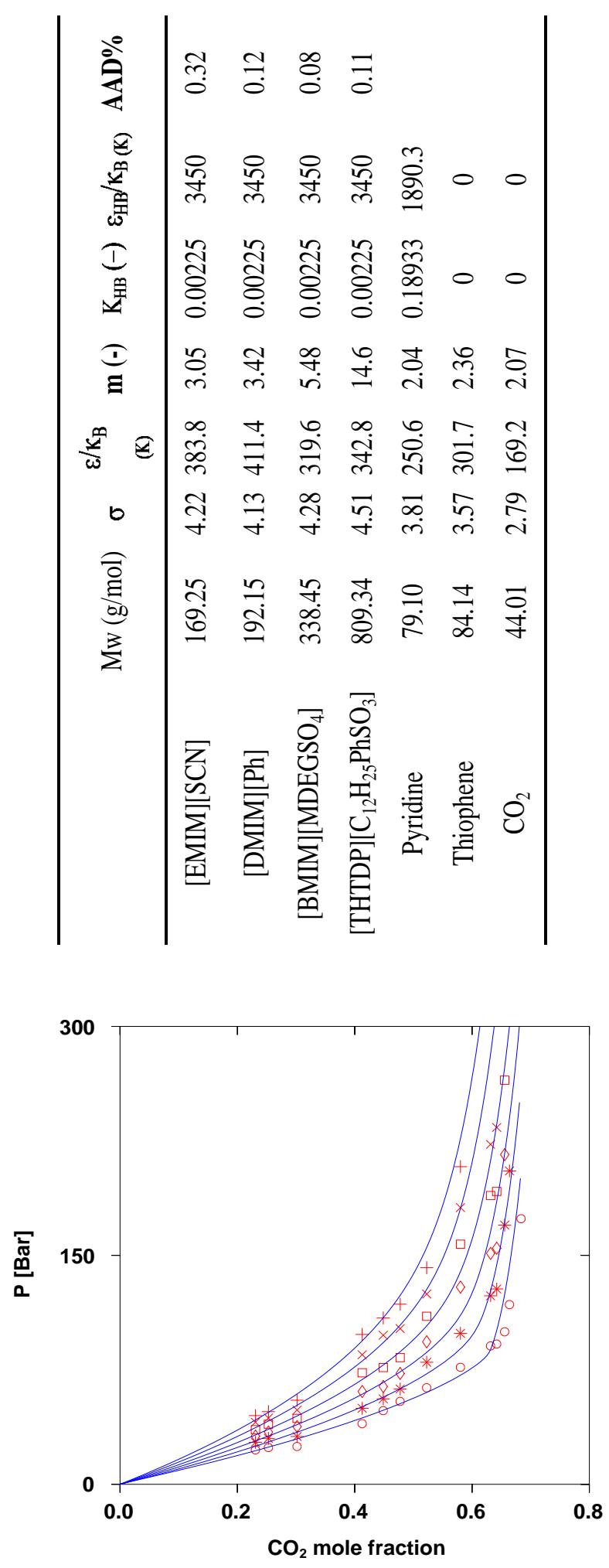

Figure 3. Solubility of $\mathrm{CO} 2$ in the $[\mathrm{BMIM}]\left[\mathrm{MDEGSO}_{4}\right]$ at different temperatures: $\mathrm{T}=313 \mathrm{~K}(\mathrm{\circ}), \mathrm{T}=323 \mathrm{~K}(*), \mathrm{T}=333 \mathrm{~K}(\diamond)$, $\mathrm{T}=343 \mathrm{~K}(\square), \mathrm{T}=353 \mathrm{~K}(\times)$ and $\mathrm{T}=363 \mathrm{~K}(+)$ with a temperaturedependent $\mathrm{k}_{\mathrm{ij}}$ parameter. Solid lines are the PC-SAFT calculations.

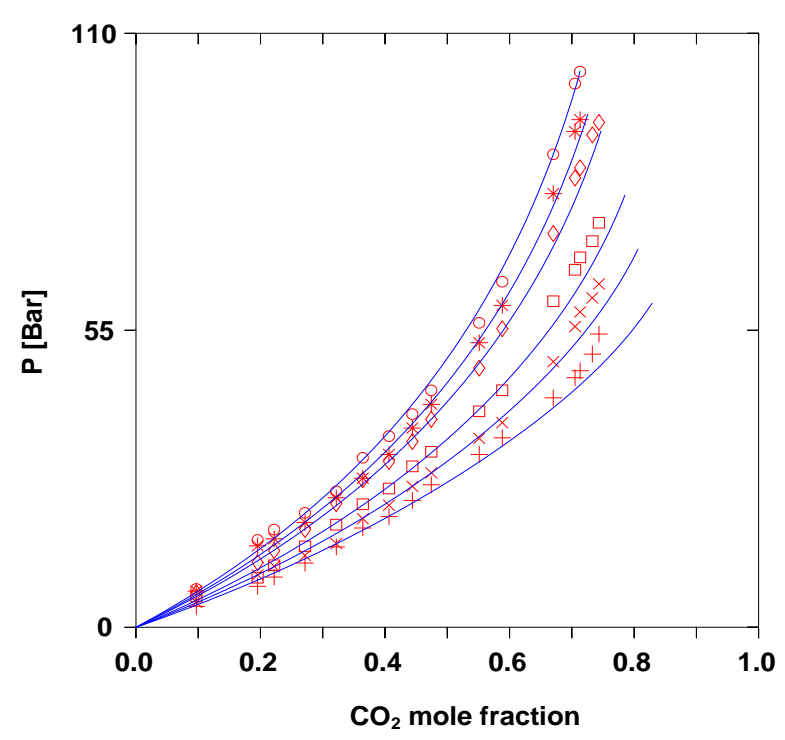

Figure 4. Solubility of $\mathrm{CO}_{2}$ in the [THTDP] $\left[\mathrm{C}_{12} \mathrm{H}_{25} \mathrm{PhSO}_{3}\right]$ at different temperatures: $\mathrm{T}=303.15 \mathrm{~K}(+), \mathrm{T}=313.15 \mathrm{~K}(\mathrm{x})$,

$\mathrm{T}=323.15 \mathrm{~K}(\square), \mathrm{T}=343.15 \mathrm{~K}(\diamond), \mathrm{T}=353.15 \mathrm{~K}(*)$ and

$\mathrm{T}=363.15 \mathrm{~K}(\mathrm{O})$ with a temperature-dependent $\mathrm{k}_{\mathrm{ij}}$ parameter. Solid lines are the PC-SAFT calculations.

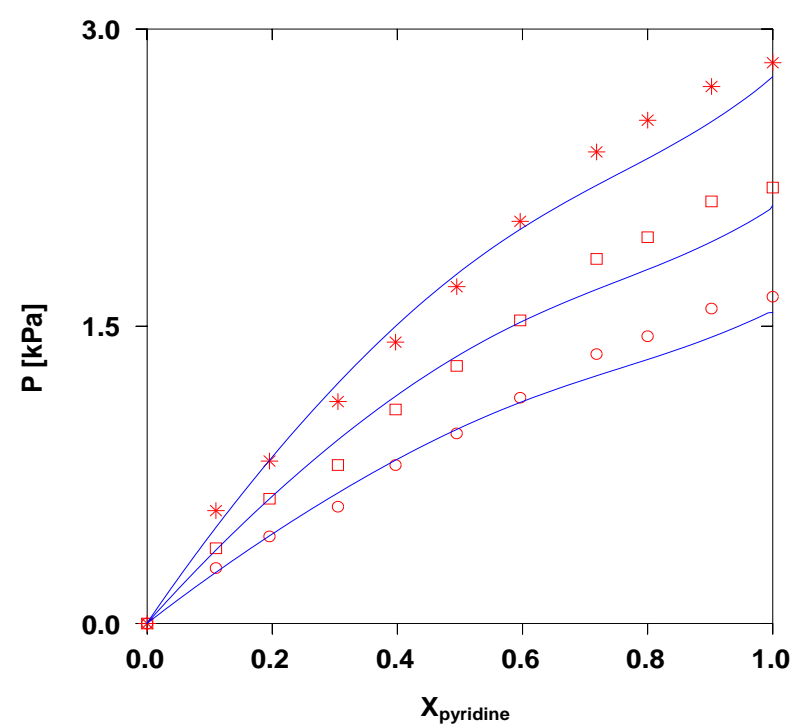

Figure 5. Experimental VLE data for the investigated binary systems $\{$ Pyridine $+[$ EMIM $][\mathrm{SCN}]\}$ at different temperatures: $\mathrm{T}=288.15 \mathrm{~K}(\circ), \mathrm{T}=293.15 \mathrm{~K}(\square)$ and $\mathrm{T}=298.15(*)$. Solid lines are the PC-SAFT calculations.

Secondly, we studied $\{$ Pyridine + ILs $\}$ at different temperatures: $\mathrm{T}=283.15 \mathrm{~K}, \mathrm{~T}=288.15 \mathrm{~K}, \mathrm{~T}=293.15 \mathrm{~K}$ and $\mathrm{T}=298.15 \mathrm{~K}$. As shown in Figure 5, a good agreement between experimental VLE data and the calculated phase diagrams using the PC-SAFT is observed for the system of $\{$ Pyridine $+[$ EMIM $][S C N]\}$. Vapor-liquid and vaporliquid-liquid equilibrium are observed for the binary system $\{$ Pyridine $+[\mathrm{DMIM}][\mathrm{Ph}]\}$ (see Figure 6 ). The existence of one or the other depends on the concentration of mixture. Through Figure 6, it was noticeable that the phenomenon of vapor-liquid-liquid equilibrium appears from 0.51 mole fraction of pyridine at $288.15 \mathrm{~K}$ and the area of VLLE decreases with the increment of temperature. Furthermore, other phase 
diagrams of systems such as $\{$ thiophene + ILs \}, \{toluene + ILs $\}$ and $\{$ water + ILs $\}$ that mainly exist in the extractive desulfurization process can be well represented by the PC-SAFT EoS.

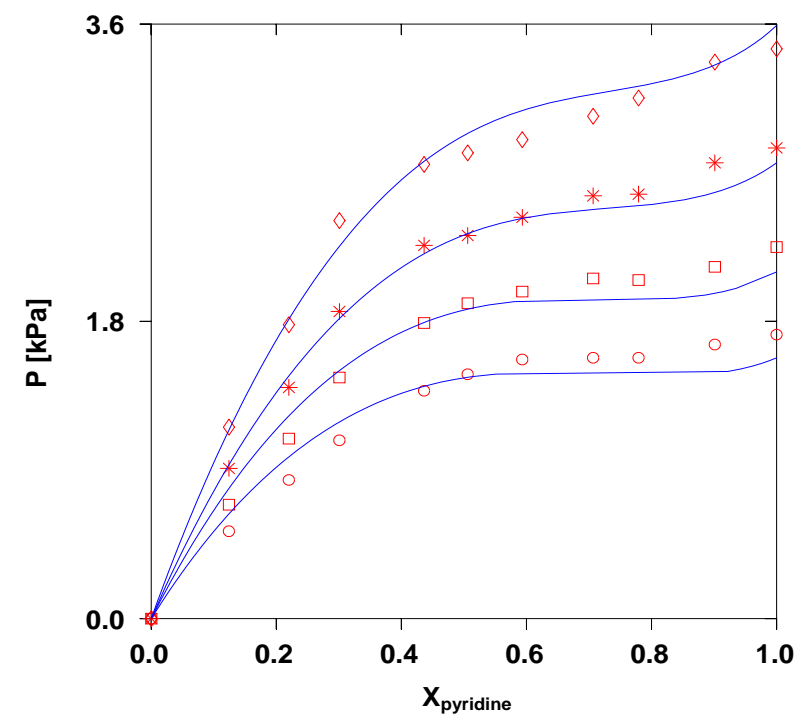

Figure 6. Experimental VLE data for the investigated binary systems $\{$ Pyridine $+[\mathrm{DMIM}][\mathrm{Ph}]\}$ at different temperatures:

$\mathrm{T}=288.15 \mathrm{~K}(\mathrm{\circ}), \mathrm{T}=293.15 \mathrm{~K}(\square), \mathrm{T}=298.15 \mathrm{~K}(*)$ and

$\mathrm{T}=303.15 \mathrm{~K}(\diamond)$. Solid lines are the PC-SAFT calculations.

\section{Conclusion}

Phase diagrams of systems containing $\left\{\mathrm{ILs}+\mathrm{CO}_{2}\right\}$ and \{ILs+ pyridine $\}$ were studied in a wide range of temperatures and pressures. It was found that ILs may have a good capacity for $\mathrm{CO}_{2}$ absorption and fuels desulfurization. A thermodynamic model based on the PC-SAFT EoS was used with success in the correlation of the measured VLE data. The model provides a good description of phase diagrams of these mixtures.

\section{References}

1. M.J. Earle, K.R. Seddon, Green Chem. 721391 (2000)

2. A.L. Revelli, F. Mutelet, J.-N. Jaubert, Ind. Eng. Chem. Res. 493883 (2010)

3. F. Mutelet, A.L. Revelli, J.-N. Jaubert, L.M. Sprunger, W.E. Acree, G.A. Baker, J. Chem. Eng. Data 55234 (2010)

4. F. Mutelet, J.-N. Jaubert, M. Rogalski, J. Harmand, M. Sindt, J.L. Mieloszynski, J. Phys. Chem. B 112 3773 (2008)

5. A.L. Revelli, F. Mutelet, M. Turmine, R. Solimando, J.-N. Jaubert, J. Chem. Eng. Data 5490 (2009)

6. A.L. Revelli, F. Mutelet, J.-N. Jaubert, J. Chromatogr. A 12164775 (2009)

7. J. Gross, G. Sadowski, Ind. Eng. Chem. Res. 401244 (2001)

8. Y.S. Chen, F. Mutelet, J.-N, Jaubert, J. Phys. Chem. B 11614375 (2012)

9. S.H. Huang, M. Radosz, Ind. Eng. Chem. Res. 29 2284 (1990)
10. D. Van Niekerk, F. Castro-Marcano, C.M. Colina, J.P. Mathews, Energy Fuels 252559 (2011) 